\title{
Cable-Fire Tests under the Raised Floor of Data-Processing Installations
}

\author{
KLAUS MARTIN \\ Allianz Versicherungs-AG \\ Munich, West Germany
}

\section{ABSTRACT}

Fire tests were performed for various cable types and layouts under practical conditions. Surveys were carried out in a number of dataprocessing centers to determine a cable layout that meets the requirements of data-processing installations. The following tests were carried out: Flaming of cables outside the raised floor, flaming of cables under the raised floor and flaming of a cable support with cables under the raised floor. One litre of $n$-hexane, which was electrically ignited, served as ignition source. Thermocouples were used to measure the temperature course at many measuring points and the course of the fire was documented photographically. When the cables were flamed outside the space under the raised floor, the fire did not spread. When the cables were flamed under the raised floor, fire damage to the cables were more extensive, the cables spread the fire from the space under the raised floor into the test room. When only coaxial cables with improved fire-resistant characteristics were used, the extent of the damage was restricted to the area of the ignition vessel. The conclusions are briefly discussed with respect to fire protection measures.

\section{INTRODUCTION}

Automatic data-processing is more and more becoming part and parcel of the every-day routine in a great many areas of our economy. Company data is entered into electronic data-processing systems and controlled by these systems; virtually all departments take advantage of data-processing. Consequently, the question pertaining to the prevention of damage to data-processing systems, as well as that with regard to system availability have become more important than ever.

The most significant hazards that threaten data-processing installations are unusual environmental hazards resulting from water, heat, smoke and corrosive gases that may occur as a result of accidents, fires or other potential sources of damage. Protecting DP installations from damage caused by water is primarily a matter of taking the necessary precautions during the building phase of the premises. Such precautions, as well as technical protective devices help to reduce or prevent damage in case of fire. A great many DP installa- 
tions are nowadays protected by burglar alarm systems and highly sophisticated access-control systems prevent unauthorized persons from entering certain areas.

Data-processing installations with their costly equipment represent an extraordinary risk both to the company that owns them and to the insurer. Even if the damage to equipment is only slight, corrosive fumes may result in extensive damage when they lead to interruption of work.

\section{OBJECTIVES}

In general, the behaviour of cables in raised floors of data-processing installations is not quite clear when it comes to a fire; consequently, the same is true with regard to fire-protection measures in respect of such floors. Despite the fact that this matter has been discussed for many years, it has been impossible to find satisfactory answers to the various questions, mainly due to the lack of fire tests. Furthermore, two conflicting opinions prevail:

- The raised floor must be protected by a smoke detector and equipped with automatic fire extinguishers as the damage under the raised floor would otherwise be considerable of a fire were to break out.

- If special fire-resistant cables are used, neither a smoke detector, nor automatic fire extinguishers are required since the fire cannot spread via the cables.

Fire tests carried out under realistic conditions in the fire-test room of Allianz insurance company served the purpose of clarifying the existing uncertainties. Results from such tests may help to come to a better assessment of the risk that is run by departments whose contribution to the overall success of a company is vital.

\section{CABIE CONFIGURATION AND LAYOUT}

In order to determine a cable layout that meets the requirements of data-processing installations, surveys were carried out in a number of data-processing centers. They were selected from various areas, such as business services, administration, research, production control, etc. Apart from the configuration, the nature of the cables, their cross sections and layout under the raised floor was also of importance since this can have a decisive effect on their behavior in case of fire. A further distinction was made between system-internal cables, having improved fire-resistant characteristics, and conventional commercially available cables. Altogether some 20 surveys of existing DP installations were made. The surveys revealed that cables under raised floors are not normally grouped in bundles in accordance with their cross sections. Invariably combinations of different types of cable and different cross sections were found, with heavy concentrations of cables in certain areas and virtually no cables in others.

The surveys revealed the following average configuration:

75 \% system-internal cables

25 \% commercially available cables 
The outer diameters of the system-internal cables ranged from $10 \mathrm{~mm}$ to $40 \mathrm{~mm}$ and those of the commercially-available cables from $0.5 \mathrm{~mm}$ to $20 \mathrm{~mm}$.

\section{SETUP OF THE TEST ENVIRONMENT}

Raised floor

A raised floor measuring $4.2 \mathrm{~m} \times 4.2 \mathrm{~m}$ (size of the floor panels $60 \mathrm{~cm} \times 60 \mathrm{~cm}$ ) was installed in the test room in such a way that it was enclosed at two sides by two of the walls of the room. The two open sides were closed off by means of plasterboard. A plexiglass window in the plasterboard permitted observation of the fire under the raised floor. The clearance under the raised floor was $500 \mathrm{~mm}$.

The floor panels rested on steel uprights with pressurecast aluminum supporting platforms. The floor panels themselves were made of highly-compressed chipboard with a zinc-plated steel lining glued to the bottom and carpet at the top. Two of the floor panels showed a cutout measuring $300 \times 150 \mathrm{~mm}$ through which the cables were run. $30 \%$ of the floor panels were ventilation panels (figure 1).

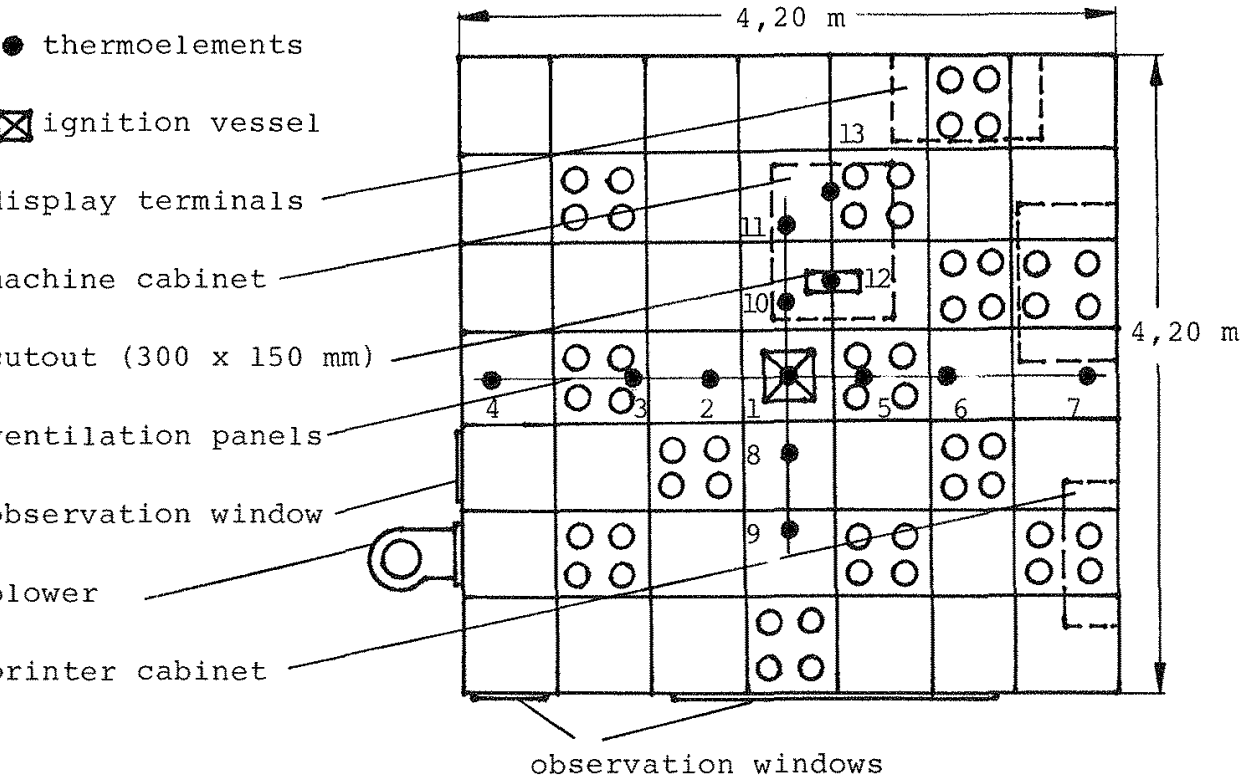

figure 1: Setup of the test environment 
Two display terminals and the cabinet of a printer were placed on the raised floor in order to be able to determine the impact of chloride contained in the fumes. A cabinet placed over one of the cutouts served to simulate actual positioning of equipment and cables in the second test.

\section{Cables}

In accordance with our findings in the field, an average cable configuration was used under the raised floor. There was an unsystematic arrangement of the cables above the ignition vessel in the first and second test. In the third test, single coaxial cables were laid on a metal cable support $(22 \times 6 \times 300 \mathrm{~cm})$. The cable support was parallel with the observation window, and its distance to the lower floor was $220 \mathrm{~mm}$. Cable configuration for all tests see table 1 .

In tests 1 and 2 , ten system-internal cables and one commerciallyavailable power cable emerged from the cutout in the floor; in test 3 they were replaced with 75 coaxial cables.

\section{Ventilution}

In the majority of all the DP installations that were surveyed, ventilation occurs via the raised floor. The air is blown into the room through openings in the floor, and extracted via the ceiling. For this reason, the tests were carried out only in ventilated raised floors.

TEST 1 AND 2

\section{System-internal cables:}

13 standard interface cables

3 standard interface cables, shielded

2 modem attachment cables, shielded

2 control cables, shielded

2 power-supply cables

1 main control cable

1 power cable

1 signal cable, shielded outer diameter

$23 / 28 \mathrm{~mm}$
$23 \mathrm{~mm}$
$10 \mathrm{~mm}$
$10 \mathrm{~mm}$
$10 \mathrm{~mm}$
$15 \mathrm{~mm}$
$40 \mathrm{~mm}$
$20 \mathrm{~mm}$

\section{External cables:}

4 power-supply cables, shielded

$20 \mathrm{~mm}$

4 power-supply cables

$13 \mathrm{~mm}$

3 PTT cables

1. plastic cable support $(20 \times 6 \times 300 \mathrm{~cm})$

$5 \mathrm{~mm}$

TEST 3

228 coaxial cables

$6 \mathrm{~mm}$ 
The air that was blown into the raised floor by a radial blower corresponded with an air exchange of 25 times.

The fumes were permanently extracted from the fire-test room and replaced with Eresh air. The air was let out of the raised floor through 14 ventilation panels. Each of these ventilation panels had 4 openings with a diameter of $120 \mathrm{~mm}$. Plastic dust traps in the form of tapered baskets were placed in each of the openings. The openings themselves were covered with air-outlet covers (of the whirl type), made of cast aluminum.

\section{Ignition source}

In test 1 the ignition source was placed on the raised floor under the cables emerging from the cutout. In tests 2 and 3 it was placed on the lower floor under the stacked cables and under the cable support, respectively. The ignition vessel was a porcelain dish, $35 \mathrm{~cm}$ in diameter, and $9 \mathrm{~cm}$ high. Prior to each test 1 liter of $\mathrm{n}$ hexane $\left(\mathrm{C}_{6} \mathrm{H}_{14}\right)$ was poured into the dish. The hexane was ignited electricaliy.

\section{Measuring the temperature}

The temperature was measured by means of Ni-CrNi jacketed thermoelements with a diameter of $3 \mathrm{~mm}$. These were installed under the raised floor at a distance of $400 \mathrm{~mm}$ from the lower floor. The distance between the thermo-elements and the ignition vessel was $50 \mathrm{~cm}$. Further thermo-elements were placed at the point where the cables emerged from the raised floor and at the end of the emerging cables. The temperature was continuously recorded during the tests.

\section{-TEST PROCEDURE}

Ignitial tests

The time during which I liter of n-hexane burned in the ignition vessel that was used in the tests was determined at 6 minutes.

Laboratory tests revealed the behavior of the cables in a fire.

\section{Main tests}

The following tests were carried out:

1. Flaming of the cables outside the raised floor.

2. Flaming of the cables under the raised floor.

3. Flaming of a cable support with cables under the raised floor.

A chronological summary of the events that occurred during the above-mentioned tests was made. 
Flaming of the cables outside the raised floor (test 1 )

After the hexane had been ignited, it burned with a flame approximately $50 \mathrm{~cm}$ tall. After one minute, dark smoke developed. Smoke development increased further and within five minutes the entire fire-test room was filled with smoke.

When the hexane was burnt, the cable insulation continued to burn. The flames spread beyond the ignition vessel. In this test, however, there was hardly any evidence of burnt cables beyond the range of action of the flames in the ignition vessel. There was no dripping of flames from the cable insulation. The fire did not spread into the space under the raised floor, not did the temperature under the raised floor increase. The temperature of the copper conductors at the end of the cables increased to approximately $144^{\circ} \mathrm{C}$ as a result of thermal conduction.

27 minutes after the ignition the last burning cable extinguished.

Flaming of the cables under the raised floor (test 2)

After the hexane had been ignited, the flames reached the underside of the floor panels. After 30 seconds black smoke emerged from the raised floor. The intensity of the fire was increased as a result of the fact that the flames bounced off the underside of the raised floor. After one minute, the first few flames emerged from the ventilation opening; the plastic dust traps had melted. The smoke continued to develop rapidly and thickly. After some three minutes, pitch-black smoke had filled the fire-test room. After that the smoke continued to increase. After six minutes the light of the halogen photo lamp was no longer visible. This thick smoke lasted until the loth minute.

After some 20 minutes there was a real fire under the raised floor of the fire-test room, although the raised floor was still an uninterrupted surface. After the $23 \mathrm{rd}$ minute, the temperature over the ignition source, which had first fallen, began to rise again (figure 2: thermoelement measuring points 1 - 8, figure 3: thermoelement measuring points $9-13$ ).

It is likely that at that time the floor boards began to burn. It appeared later that the metal sheeting on the underside had become detached. In the 30 th minute some of the floor panels collapsed. One supporting platform of the steel uprights had melted gompletely, two others had disintegrated partly. In an area of $1.62 \mathrm{~m}^{2}$ the cables were burned completely. In the direction of the airstream the damage was greater. The flames reached the cabinet over the cutout; it burned out completely and beyond repair. The cables emerging from the raised floor burned completely (figure 4). 


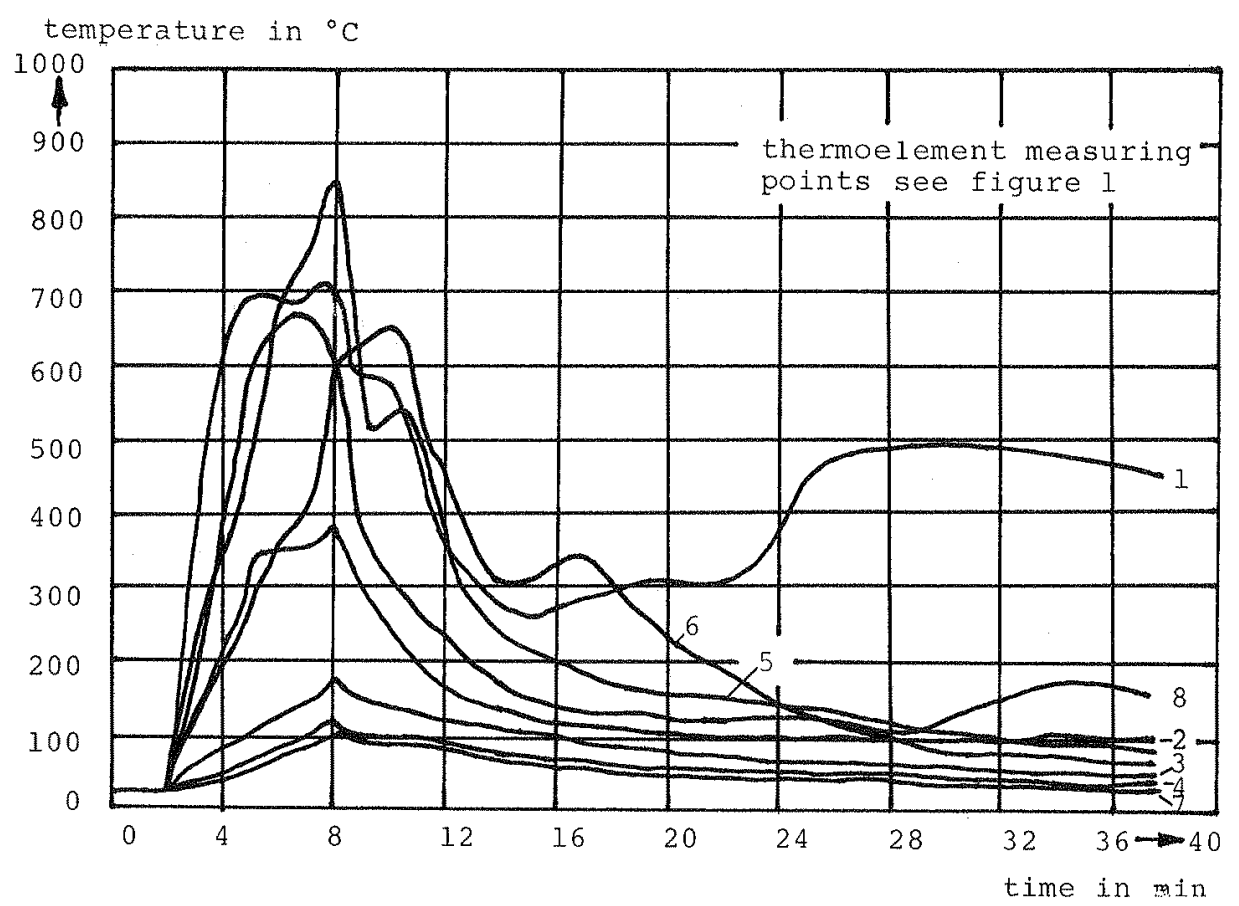

figure 2: Temperature-time-recordings (test 2, measuring points 1-8)

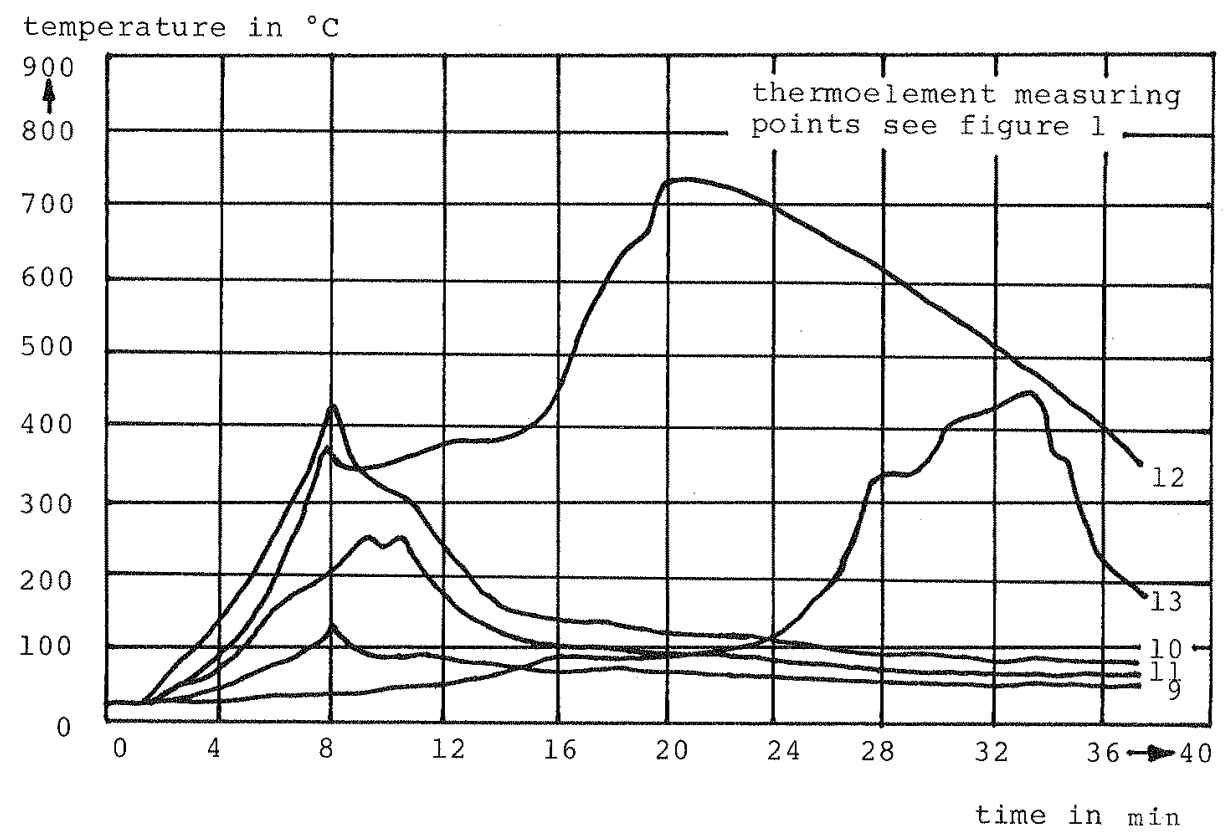

figure 3: Temperature-time-recordings (test 2, measuring points 9-13) 
- molten suporting platforms

molten dust traps

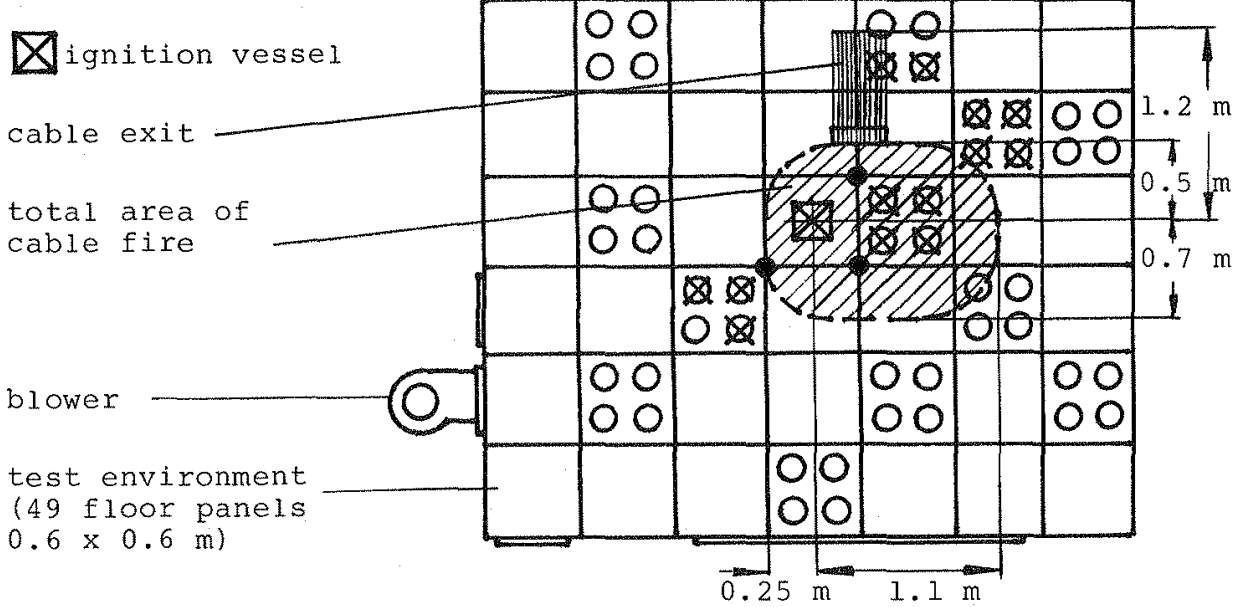

figure 4: Extent of damage in test 2

The evaluation of the recorded temperatures showed that temperatures ranging from $650^{\circ} \mathrm{C}$ to $800^{\circ} \mathrm{C}$ were maintained until all the hexane had burned away; subsequently the temperature fell up to the 15 th minute to approximately $300^{\circ} \mathrm{C}$. From the moment when the floor panels began to burn, the temperature increased to approximately $500{ }^{\circ} \mathrm{C}$ and remained at that level until the fire was extinguished.

After 35 minutes the first attempt to extinguish the fire with manually operated $\mathrm{CO}_{2}$ fire extinguishers was unsuccessful. After the 40 th minute, the fire was extinguished with water.

Flaming of an occupied cable support under the raised floor (test 3 )

After ignition of the hexane, the flames enveloped the cable support. Smoke begins to emerge from the raised floor after 1.15 minutes. After two minutes the first few flames emerged from the ventilation openings. After four minutes, the smoke had become thicker. The hexane in the ignition vessel burned for approximately seven minutes. Small flames were still visible at the top of the cables.

Cindered cables were found only where the flames had been able to get at them: under the cable support at the oval holes and above the cable support at the top layer of cables. 82 coaxial cables remained undamaged. 


\section{CONCLUSIONS}

The following conclusions may be drawn from the initial tests:

- All raised floors in DP installations that were surveyed contained a mixture of system-internal cables and external (commercially available) cables.

- Invariably, cables of different outer diameters were found.

- Each time when an installation is extended or replaced, new cables are supplied with the systems. Because only in very few cases the old cables are removed, system extension gener ally means more damage in case of fire.

- The cable layout under the raised floor was generally unsystematic and in layers.

- All raised floors that were inspected were ventilated.

- The design and the materials of the raised floor used in the fire test conformed with standard practice.

- Laboratory tests showed that the system-internal cables with improved fire-resistant characteristics have these characteristics only with regard to the outer sheating. The sheated internal wires showed a normal behavior in the fires.

- The smoke produced by system-internal cables with improved fireresistant characteristic varies, and can be extraordinarily intensive.

The following conclusions may be drawn from the main tests:

- When the cables were flamed outside the space under the raised floor, the fire did not spread. After the hexane was burned up, the cables continue to burn for another 20 minutes or so until. they extinguished. The extent of the damage was restricted to the local area, and the cables did not spread the fire into the space under the raised floor.

- When the cables were flamed under the raised floor, fire damage to the cables was more extensive in the direction of the air flow (maximum damage at a distance of $1.1 \mathrm{~m}$ from the ignition vessel!). Qutside this area, the cables under the raised floor were undamaged. The test was stopped after 40 minutes and the fire was extinguished with water.

- The cables spread the fire from the space under the raised floor into the test room; the cables burned out completely, and the cabinet that served to simulate a piece of DP equipment was roasted. We must therefore assume that - in the event of a fire the equipment in the vicinity of the seat of the fire is bound to be damaged by the fire.

- When only coaxial cables with improved fire-resistant characteristics were used, the extent of the damage was restricted to the area of the ignition vessel. The flames extinguished of their own accord after approximately 10 minutes. The fire did not spread into the room.

- If a fire breaks out under a raised floor, an extremely fast development of thick smoke must be expected (no visibility after 6 minutes). 
- An examination of the equipment used showed that the impact_of chlorige ions as a result of the fumes amounted to $10 \mathrm{\mu g} \mathrm{Cl}-$ per $\mathrm{cm}^{2}$; this exceeds the limit beyond which repair is impossible.

- Premature detachment of the metal iining glued to the underside of the floor panels resulted in spreading of the fire. The smoldering floor panels were extinguished with water; the use of $\mathrm{CO}_{2}$ was unsuccessful.

- The floor over the ignition vessel collapsed prematurely because the supporting aluminum platforms for the floor panels melted away.

- Burning drops of cable insulation were not observed.

\section{SUMMARY}

The tests showed that the fire protection of raised floorsin dataprocessing installations requires at least the use of smoke detectors. Their number and position should be governed by the influence of the ventilation, and the display system must permit fast location of the source of the smoke. Damage resulting from corrosive fumes and intensive smoke must be expected after a relatively short time, and spreading of the fire to the equipment via the ventilation openings can be prevented only by an automatic fire extinguishing system. The testshave also shown that mechanical fastening of the metal lining on the underside of the floor panels will prevent the lining from becoming detached prematurely and the fire from spreading. The supporting platforms for the raised floor should be made of steel, because melting of the aluminum platforms causes the floor to collapse, which in turn can cause the fire to spread and constitutes a hazard to the firemen. 